\title{
Effect of $\mathrm{Li}^{+}$-ion on enhancement of photoluminescence in $\mathrm{Gd}_{2} \mathrm{O}_{3}: \mathrm{Eu}^{3+}$ nanophosphors prepared by combustion technique
}

\author{
N. Dhananjaya ${ }^{\mathrm{a}, \mathrm{b}}$, H. Nagabhushana ${ }^{\mathrm{c}, *}$, B.M. Nagabhushana ${ }^{\mathrm{d}}, \mathrm{B}$. Rudraswamy $^{\mathrm{a}}$, \\ C. Shivakumara ${ }^{\mathrm{e}}$, R.P.S. Chakradhar $\mathrm{f}^{, *, 1}$ \\ a Department of Physics, J.B. Campus, Bangalore University, Bangalore 560 056, India \\ ${ }^{\mathrm{b}}$ Department of Physics, B.M.S. Institute of Technology, Bangalore 560 064, India \\ ' Department of PG studies \&' Research in Physics, University Science College, Tumkur University, Tumkur 572 103, India \\ d Department of Chemistry, M.S. Ramaiah Institute of Technology, Bangalore 560 054, India \\ e Solid State and Structural Chemistry Unit, Indian Institute of Science, Bangalore 560 012, India \\ ${ }^{\mathrm{f}}$ Central Glass and Ceramic Research Institute (CSIR), Kolkata 700 031, India
}

\section{A R T I C L E I N F O}

\section{Article history:}

Received 29 September 2010

Received in revised form 29 October 2010

Accepted 3 November 2010

Available online 10 November 2010

\section{Keywords:}

Nanophosphor

$\mathrm{Eu}^{3+}$

Gadolinium oxide

$\mathrm{Li}^{+}$co-doping

XRD

SEM

UV-VIS

Photoluminescence

\begin{abstract}
A B S T R A C T
$\mathrm{Gd}_{2} \mathrm{O}_{3}: \mathrm{Eu}^{3+}$ ( $\left.4 \mathrm{~mol} \%\right)$ nanophosphor co-doped with $\mathrm{Li}^{+}$ions have been synthesized by low-temperature solution combustion technique in a short time. Powder X-ray diffractometer (PXRD), scanning electron microscopy (SEM), Fourier transform infrared spectroscopy (FT-IR), UV-VIS and photoluminescence (PL) techniques have been employed to characterize the synthesized nanoparticles. It is found that the lattice of $\mathrm{Gd}_{2} \mathrm{O}_{3}: \mathrm{Eu}^{3+}$ phosphor transforms from monoclinic to cubic as the $\mathrm{Li}^{+}$-ions are doped. Upon $254 \mathrm{~nm}$ excitation, the phosphor showed characteristic luminescence ${ }^{5} \mathrm{D}_{0} \rightarrow{ }^{7} \mathrm{~F}_{J}(J=0-4)$ of the Eu $\mathrm{u}^{3+}$ ions. The electronic transition located at $626 \mathrm{~nm}\left({ }^{5} \mathrm{D}_{0} \rightarrow{ }^{7} \mathrm{~F}_{2}\right)$ of Eu${ }^{3+}$ ions was stronger than the magnetic dipole transition located at $595 \mathrm{~nm}\left({ }^{5} \mathrm{D}_{0} \rightarrow{ }^{7} \mathrm{~F}_{1}\right)$. Furthermore, the effects of the $\mathrm{Li}^{+}$co-doping as well as calcinations temperature on the PL properties have been studied. The results show that incorporation of $\mathrm{Li}^{+}$ ions in $\mathrm{Gd}_{2} \mathrm{O}_{3}: \mathrm{Eu}^{3+}$ lattice could induce a remarkable improvement of their PL intensity. The emission intensity was observed to be enhanced four times than that of with out $\mathrm{Li}^{+}-$doped $\mathrm{Gd}_{2} \mathrm{O}_{3}$ : $\mathrm{Eu}^{3+}$.
\end{abstract}

(C) 2010 Elsevier B.V. All rights reserved.

\section{Introduction}

Nowadays, phosphors with high performances such as sufficient brightness, fast response and long term stability are required for the progress of modern luminescence devices [1]. The rare earth activated oxide phosphors have good luminescent characteristics, stability in high vacuum, and absence of corrosive gas emission under electron bombardent when compared to currently used sulfide based phosphors. The red-emitting phosphors doped with trivalent rare-earth (RE) ions have been widely used in the development of emissive display and tricolor lamp industry for two decades. In the past, $\mathrm{Li}^{+}$ion has been introduced in to different oxide hosts such as $\mathrm{Y}_{2} \mathrm{O}_{3}: \mathrm{Eu}^{3+}[2], \mathrm{Gd}_{2} \mathrm{O}_{3}: \mathrm{Eu}^{3+}$ [3], $\mathrm{SnO}_{2}: \mathrm{Eu}^{3+}$ [4], acting as a co-activator and charge compensator. It has been found that the PL intensity was substantially enhanced after $\mathrm{Li}^{+}$doping. It has

\footnotetext{
* Corresponding authors.

E-mail addresses: bhushanvl@rediffmail.com (H. Nagabhushana), sreechakra72@yahoo.com, chakra72@gmail.com (R.P.S. Chakradhar). 1 Present address: Scientist, CSIR-NAL, Bangalore 560 017, India.
}

recently been reported that $\mathrm{Li}^{+}$site could result in the enhancement of up conversion emission in $\mathrm{Gd}_{2} \mathrm{O}_{3}: \mathrm{Eu}^{3+}$ [5]. It indicates that the improved up-conversion intensity may originate from the break of local crystal field symmetry around rare-earth ions by the $\mathrm{Li}^{+}$doping. Since $\mathrm{Li}^{+}$ion is very small, it can easily enter the host lattice, occupying not only the substitutional sites but also the interstitial sites [6]. Both the substitutional $\mathrm{Gd}^{3+}$ ions and the occupation of interstitial sites can break the symmetry of the crystal field around the rare-earth ions and the break can enhance the PL intensity.

The $\mathrm{Li}^{+}$ions, even in very small quantities as the dopant, frequently play an important role in increasing the luminescent efficiency of phosphors. Therefore, alkali metal ions such as $\mathrm{Li}^{+}$, $\mathrm{Na}^{+}, \mathrm{K}^{+}$were used to modify the local site symmetry of $\mathrm{Eu}^{3+}$ for improving the luminescence efficiency, owing to their chemical nature of low oxidation states and distinct ionic radii. A number of methods such as combustion [7], solid state [5], sol-gel [8] were employed to fabricate the $\mathrm{Gd}_{2} \mathrm{O}_{3}: \mathrm{Eu}^{3+}$ nanoparticles. Among, these methods, solution combustion technique is more attractive owing to the advantages of the simple equipment, low process temperature, time consumption, high purity and easily controlled particle size. 
To the best of our knowledge, the systematic studies on $\mathrm{Li}^{+}$ co-doping on the structural and PL studies of $\mathrm{Gd}_{2} \mathrm{O}_{3}$ : $\mathrm{Eu}^{3+}$ is very limited. As a part of our programme on phosphor materials [9-12], here we report, the effect of $\mathrm{Li}^{+}$-ion on structural and enhancement of photoluminescence properties of $\mathrm{Gd}_{2} \mathrm{O}_{3}: \mathrm{Eu}^{3+}$ nanophosphors prepared by combustion technique. It is generally regarded that the luminescent efficiency of phosphor is reduced with the decrease of the grain size due to a large contribution of the surface states to the non-radiative transition [13]. On the other hand, a change in the composition of phosphor, such as the incorporation of $\mathrm{Li}^{+}$ ion into host material, is an effective way to enhance its luminescent performance. The role of the $\mathrm{Li}^{+}$ion is mainly attributed to the flux effect and the creation of oxygen vacancy [14]. Therefore, it is expected that the luminescent efficiency will be improved further by co-doping with several dopants.

\section{Experimental}

\subsection{Synthesis of $\mathrm{Li}^{+}$-doped $\mathrm{Gd}_{2} \mathrm{O}_{3}: \mathrm{Eu}^{3+}$ nanoposphors}

The starting chemicals used for the preparation of $\mathrm{Gd}_{2} \mathrm{O}_{3}: \mathrm{Eu}^{3+}\left(\mathrm{Li}^{+}\right)$nanophosphors were of analar grade gadolinium nitrate $\left[\mathrm{Gd}\left(\mathrm{NO}_{3}\right)_{3}\right]$, europium nitrate $\left[\mathrm{Eu}\left(\mathrm{NO}_{3}\right)_{3}\right]$ and lithium nitrate $\left[\mathrm{LiNO}_{3}\right]$. The oxalyl dihydrazide [ODH: $\mathrm{C}_{2} \mathrm{H}_{6} \mathrm{~N}_{4} \mathrm{O}_{2}$ ] is used as a fuel for combustion synthesis and was prepared in our laboratory [15]. An aqueous solution containing stoichiometric amounts of gadolinium nitrate, europium nitrate, lithium nitrate and ODH have been taken in a cylindrical Petri dish of $\sim 300 \mathrm{ml}$ capacity. The excess water is allowed to evaporate by heating over a hot plate until a wet powder is left out. Then the Petri dish is introduced into a muffle furnace maintained at $400 \pm 10^{\circ} \mathrm{C}$. The reaction mixture undergoes thermal dehydration and ignites at one spot with liberation of gaseous products such as oxides of nitrogen and carbon. The combustion of $\mathrm{ODH}$ is exothermic and releases the energy required for the synthesis. The combustion propagates throughout the reaction mixture without further need of any external heating, as the heat of reaction is sufficient for the decomposition of redox mixture. The flame temperature was found to be $1000 \pm 50^{\circ} \mathrm{C}$, which persists for few seconds, and was measured by an optical pyrometer placed inside the muffle furnace. The flow chart for the synthesis $\mathrm{Gd}_{2} \mathrm{O}_{3}: \mathrm{Eu}^{3+}\left(\mathrm{Li}^{+}\right)$phosphor is given in Fig. 1

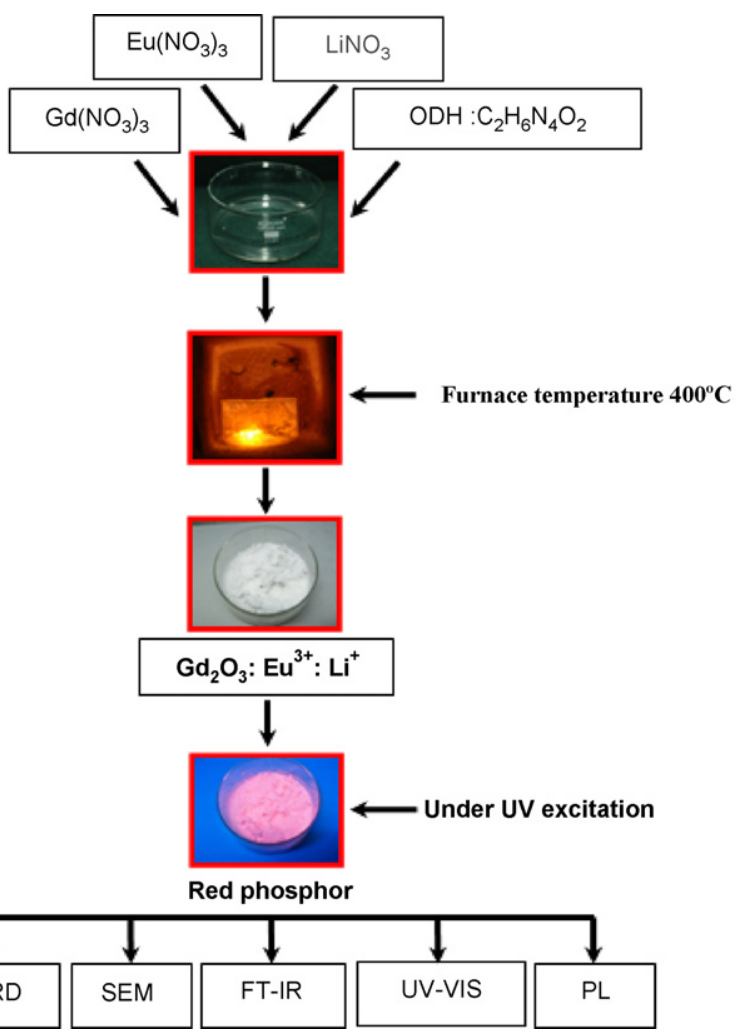

Fig. 1. Flow chart for the synthesis of $\mathrm{Gd}_{2} \mathrm{O}_{3}: \mathrm{Eu}^{3+}\left(\mathrm{Li}^{+}\right)$nanophosphor.

\subsection{Instruments used}

The phase purity of the nanophosphors is examined by powder X-ray diffractometer (PXRD) (PANalytical X'Pert Pro) using $\mathrm{CuK}_{\alpha}$ radiation with a nickel filter was used to estimate the crystallinity of the phases. The surface morphology of the product is examined by Scanning Electron Microscopy (SEM) (JEOL JSM 840A) by sputtering technique with gold as covering contrast material. The FT-IR studies have been performed on a Perkin Elmer Spectrometer (Spectrum 1000) with KBr pellets. The UV-VIS absorption of the samples was recorded on SL 159 ELICO UV-VIS Spectrophotometer. The photoluminescence $(\mathrm{PL})$ measurements were performed on a Shimadzu Spectroflourimeter (Model RF 510) equipped with 150 W Xenon lamp as an excitation source.

\section{Results and discussion}

Fig. 2(a) shows the powder X-ray diffraction patterns of $\mathrm{Gd}_{2} \mathrm{O}_{3}: \mathrm{Eu}^{3+}: \mathrm{Li}^{+}(0-8 \mathrm{~mol} \%)$ phosphors calcined at $800^{\circ} \mathrm{C}$ for $3 \mathrm{~h}$. The $\mathrm{Gd}_{2} \mathrm{O}_{3}$ : $\mathrm{Eu}^{3+}$ nanopowders indexed to mixed phase of monoclinic (JCPDS no. 43-1015) and cubic (JCPDS no. 86-2477) structure respectively. The sharp and intense peaks clearly show the crystalline nature of the sample. As $\mathrm{Li}^{+}$concentration increases the mixed phase becomes more likely to be cubic phase. The ratio of the peak values $I_{C}(222) / I_{M}(402)$ (Intensity of cubic phase to monoclinic phase) increased from 1.17 to 4.79 . The crystallite size was calculated from the broad PXRD peaks using the Scherer's equation [16]

$$
d=\frac{0.9 \lambda}{\beta \cos \theta}
$$
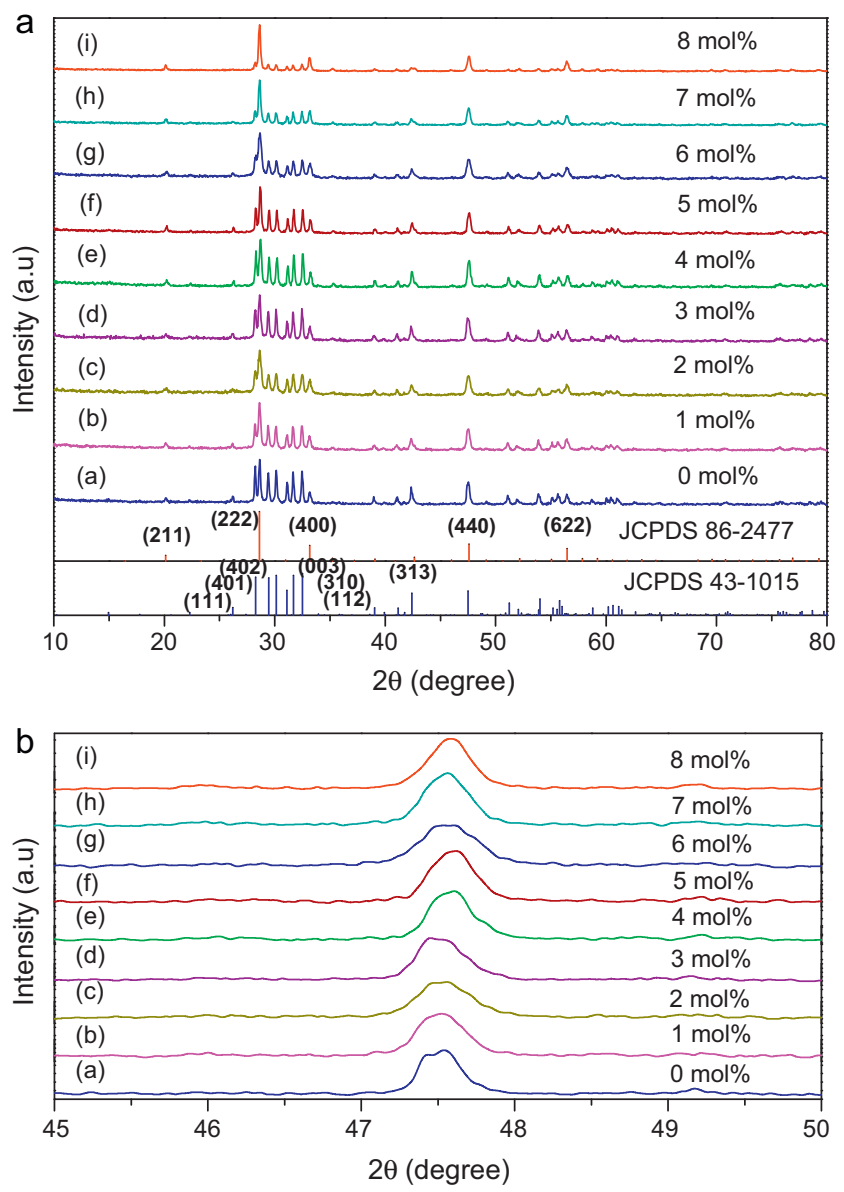

Fig. 2. (a) PXRD patterns of $\mathrm{Gd}_{2} \mathrm{O}_{3}: \mathrm{Eu}^{3+}: \mathrm{Li}^{+}(0-8 \mathrm{~mol} \%)$ nanophosphors calcined at $800{ }^{\circ} \mathrm{C}$ for $3 \mathrm{~h}$. (b) PXRD patterns of $\mathrm{Gd}_{2} \mathrm{O}_{3}: \mathrm{Eu}^{3+}: \mathrm{Li}^{+}(0-8 \mathrm{~mol} \%)$ nanophosphors (at $2 \theta=47.5(440))$ calcined at $800^{\circ} \mathrm{C}$ for $3 \mathrm{~h}$. 
Table 1

Parameters calculated with respect various $\mathrm{Li}^{+}$ion concentrations.

\begin{tabular}{|c|c|c|c|c|}
\hline \multirow[t]{2}{*}{ Sample } & \multirow[t]{2}{*}{ FWHM (degree) $2 \theta=28.68^{\circ}$} & \multicolumn{2}{|l|}{ Grain size $(\mathrm{nm})$} & \multirow[t]{2}{*}{ Band gap $(\mathrm{eV})$} \\
\hline & & Scherer's method $(d)$ & W-H method $(D)$ & \\
\hline $\mathrm{Gd}_{2} \mathrm{O}_{3}: \mathrm{Eu}^{3+}$ & 0.3552 & 25.51 & 29.28 & 4.47 \\
\hline $\mathrm{Gd}_{2} \mathrm{O}_{3}: \mathrm{Eu}^{3+}: \mathrm{Li}(1 \mathrm{~mol} \%)$ & 0.3357 & 26.99 & 31.73 & 4.83 \\
\hline $\mathrm{Gd}_{2} \mathrm{O}_{3}: \mathrm{Eu}^{3+}: \mathrm{Li}(2 \mathrm{~mol} \%)$ & 0.2560 & 35.39 & 40.88 & 5.43 \\
\hline $\mathrm{Gd}_{2} \mathrm{O}_{3}: \mathrm{Eu}^{3+}: \mathrm{Li}(3 \mathrm{~mol} \%)$ & 0.2495 & 36.32 & 42.95 & 5.41 \\
\hline $\mathrm{Gd}_{2} \mathrm{O}_{3}: \mathrm{Eu}^{3+}: \mathrm{Li}(4 \mathrm{~mol} \%)$ & 0.2480 & 36.65 & 45.95 & 5.42 \\
\hline $\mathrm{Gd}_{2} \mathrm{O}_{3}: \mathrm{Eu}^{3+}: \mathrm{Li}(5 \mathrm{~mol} \%)$ & 0.2402 & 37.73 & 48.23 & 5.23 \\
\hline $\mathrm{Gd}_{2} \mathrm{O}_{3}: \mathrm{Eu}^{3+}: \mathrm{Li}(6 \mathrm{~mol} \%)$ & 0.2210 & 41.01 & 51.32 & 5.16 \\
\hline $\mathrm{Gd}_{2} \mathrm{O}_{3}: \mathrm{Eu}^{3+}: \mathrm{Li}(7 \mathrm{~mol} \%)$ & 0.2092 & 43.32 & 52.32 & 4.81 \\
\hline $\mathrm{Gd}_{2} \mathrm{O}_{3}: \mathrm{Eu}^{3+}: \mathrm{Li}(8 \mathrm{~mol} \%)$ & 0.2005 & 45.19 & 54.19 & 4.60 \\
\hline
\end{tabular}

where $d$ is the average grain size of the crystallites, $\lambda$ the incident wavelength, $\theta$ the Bragg angle and $\beta$ the diffracted full-width at half-maximum (FWHM) in radians caused by the crystallites. The mean crystallite size calculated from this method is found to be in the range $25-45 \mathrm{~nm}$.

The grain size was also calculated from the powder X-ray diffraction line broadening $(B)$ using the analysis described by Williamson and Hall (W-H) method [17].

$B \cos \theta=\varepsilon(4 \sin \theta)+\frac{\lambda}{D}$

where $B$ (FWHM in radian) is measured for different XRD lines corresponding to different planes, $\varepsilon$ is the strain developed and $D$ is the grain size. The equation represents a straight line between $4 \sin \theta$ ( $X$-axis) and $B \cos \theta$ ( $Y$-axis). The slope of line gives the strain $(\varepsilon)$ and intercept $(\lambda / D)$ of this line on the $Y$-axis gives grain size $(D)$.

The grain size determined from $\mathrm{W}-\mathrm{H}$ formula is slightly higher than those calculated using Scherrer's formula (Table 1). The small variation in the values is due to the fact that in Scherrer's formula strain component is assumed to be zero and observed broadening of diffraction peak is considered as a result of reducing grain size only. Strain continues to increase with an increase in $\mathrm{Li}^{+}$concentration. These results indicated that the host lattice dimension shrinks with the concentration of $\mathrm{Li}^{+}$from $0 \mathrm{~mol} \%$ and then begins to expand when the concentration of $\mathrm{Li}^{+}$is over $5 \mathrm{~mol} \%$. The effective ionic radius of $\mathrm{Gd}^{3+}$ ion and $\mathrm{Li}^{+}$ion are $0.94 \AA$ and $0.76 \AA$ respectively [18]. Hence, substitutes the $\mathrm{Gd}^{3+}$ ion with these smaller $\mathrm{Li}^{+}$ ion can induce the shrinking of the host lattice, whereas $\mathrm{Li}^{+}$ions occupying the interstitial sites leads to the expansion of the host lattice consequently, when the concentration of $\mathrm{Li}^{+}$ions is below $5 \mathrm{~mol} \%, \mathrm{Li}^{+}$ions occupy substitutional sites, but with higher concentrations, $\mathrm{Li}^{+}$ions begin to take interstitial sites. The both types of $\mathrm{Li}^{+}$ occupancies would break the local crystal field symmetry around the $\mathrm{Eu}^{3+}$ ions, $\mathrm{Li}^{+}$ions doping could help to break the forbidden transition, change the life time of energy levels and consequently enhance the intensity. As $\mathrm{Li}^{+}$content was increased from 0 to $4 \mathrm{~mol} \%$ crystallinity improved. However, when $\mathrm{Li}^{+}$content was increased, further to $5 \mathrm{~mol} \%$, the crystallinity decreases, this result may be induced by increase of oxygen vacancies by $\mathrm{Li}^{+}$ion substitution [19]. These oxygen vacancies in lattice weakened bond strength such that the lattice constant increased [20]. The lattice parameters to be observed shifted towards larger values due to lattice expansion with increase in $\mathrm{Li}^{+}$concentration. Occupation of $\mathrm{Li}^{+}$ion would naturally give rise to a substantial number of vacant sites in oxygen ion and then expand the lattice with decrease of crystal density. So the lattice expansion can be attributed to the weakening of bond strength due to the formation of oxygen vacancies [21]. Better crystallization and larger grain size can be regarded as the result of the $\mathrm{Li}^{+}$ions during the preparation process, which plays an important role in effectively promoting an incorporation of $\mathrm{Eu}^{3+}$ and $\mathrm{Gd}_{2} \mathrm{O}_{3}$ as well as $\mathrm{Li}^{+}$ions themselves in to the host lattice.
Fig. 2(b) shows the shift of the peak towards higher glancing angle, it is due to smaller size of $\mathrm{Li}^{+}$ion and it is conforms the incorporation of $\mathrm{Li}^{+}$ions in $\mathrm{Gd}_{2} \mathrm{O}_{3}: \mathrm{Eu}^{3+}$ lattice.

Fig. 3(a-e) shows the PXRD patterns of $\mathrm{Li}^{+}$( $4 \mathrm{~mol} \%$ ) co-doped $\mathrm{Gd}_{2} \mathrm{O}_{3}: \mathrm{Eu}^{3+}$ samples calcined at $500,600,700,800$ and $900^{\circ} \mathrm{C}$ for $3 \mathrm{~h}$. It is observed that the intensity of the PXRD peaks increases with calcination temperatures. It is noticed that the ratio of peak values, $I_{C}(222) / I_{M}(1111)$, increased from 0.79 to 1.48 with increase in calcination temperature $500-700^{\circ} \mathrm{C}$, and thereafter it start decreasing from 1.48 to 0.93 with further increase in calcinations temperature $800-900^{\circ} \mathrm{C}$.

Fig. 4 show the SEM photographs of without and with $\mathrm{Li}^{+}$ ( $6 \mathrm{~mol} \%$ ) co-doped $\mathrm{Gd}_{2} \mathrm{O}_{3}: \mathrm{Eu}^{3+}$ phosphor. The un-doped phosphors are agglomerated from few microns to a few tens of microns, fluffy and porous in nature. The agglomeration of nanoparticles is usually explained as a common way to minimize their surface free energy. The voids and pores present in the sample are due to the large amount of gases produced during combustion synthesis. In $\mathrm{Li}^{+}(6 \mathrm{~mol} \%)$ doped $\mathrm{Gd}_{2} \mathrm{O}_{3}: \mathrm{Eu}^{3+}$ phosphor, the agglomeration is reduced and particles are in spherical in shape.

Fourier transform infrared spectral studies (Fig. 5) have been carried out on all $\mathrm{Li}^{+}$-doped $\mathrm{Gd}_{2} \mathrm{O}_{3}: \mathrm{Eu}^{3+}$ samples. It is found that, the peaks around 400 and $540 \mathrm{~cm}^{-1}$ confirms the $\mathrm{Gd}-\mathrm{O}$ peak. No other peak is noticed, this conforms the purity of the compounds.

The excitation spectra of without and with $\mathrm{Li}^{+}(6 \mathrm{~mol} \%)$ doping of $\mathrm{Gd}_{2} \mathrm{O}_{3}: \mathrm{Eu}^{3+}$ phosphors are illustrated in the Fig. 6(a and b) respectively. The peak near $250 \mathrm{~nm}$ in the excitation spectrum is known as the charge transfer $(\mathrm{CT})$ peak which attributes to the transition

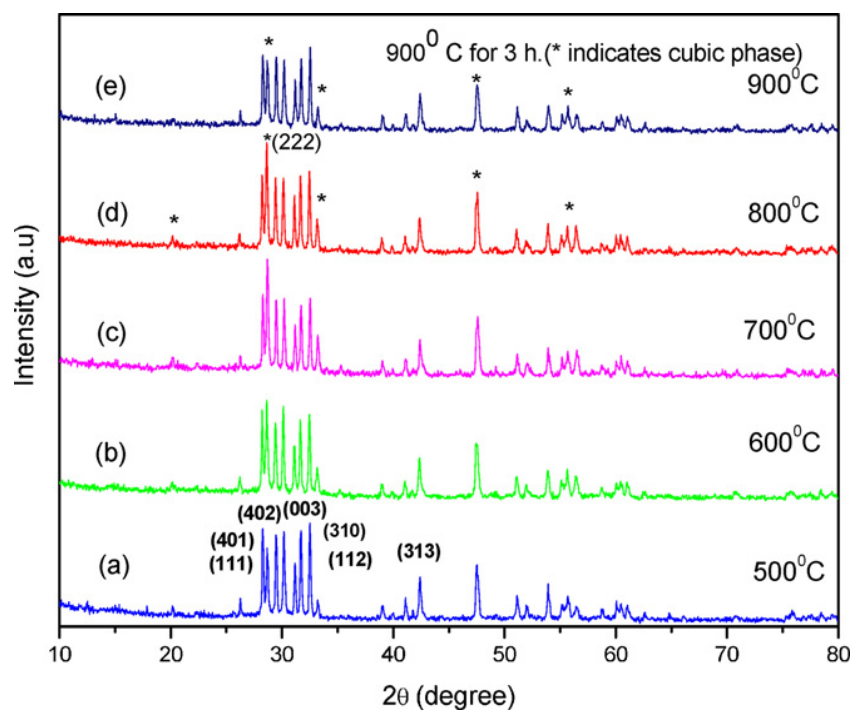

Fig. 3. PXRD patterns of $\mathrm{Gd}_{2} \mathrm{O}_{3}: \mathrm{Eu}^{3+}: \mathrm{Li}^{+}(4 \mathrm{~mol} \%)$ phosphors calcined at (a) $500{ }^{\circ} \mathrm{C}$ (b) $600{ }^{\circ} \mathrm{C}$, (c) $700^{\circ} \mathrm{C}$, (d) $800^{\circ} \mathrm{C}$ and (e) $900^{\circ} \mathrm{C}$ for $3 \mathrm{~h}$. 

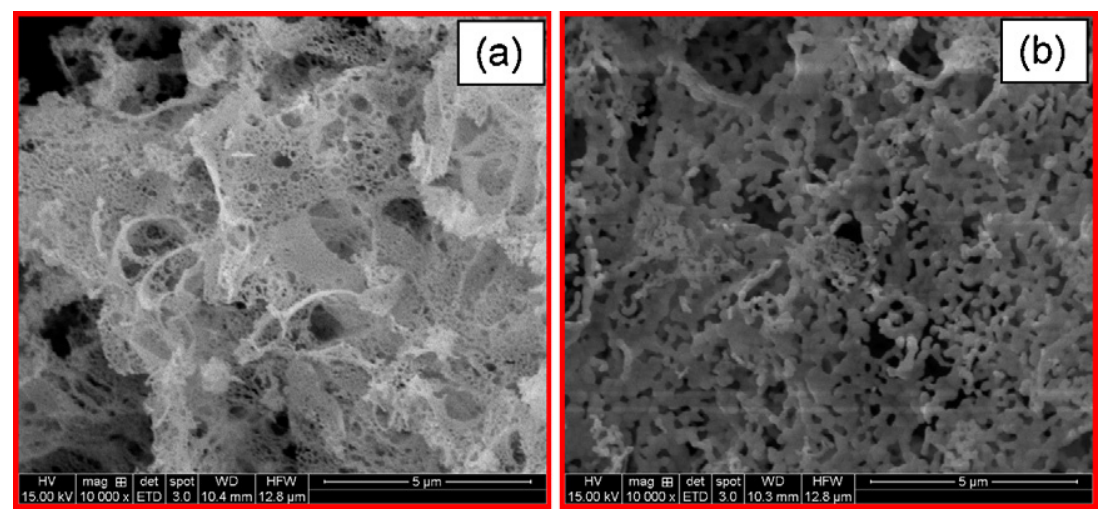

Fig. 4. SEM micrographs of nanophosphors calcined at $800^{\circ} \mathrm{C}$ for $3 \mathrm{~h}$ (a) $\mathrm{Gd}_{2} \mathrm{O}_{3}: \mathrm{Eu}^{3+}$ and (b) $\mathrm{Gd}_{2} \mathrm{O}_{3}: \mathrm{Eu}^{3+}: \mathrm{Li}^{+}\left(6 \mathrm{~mol}^{2}\right)$.

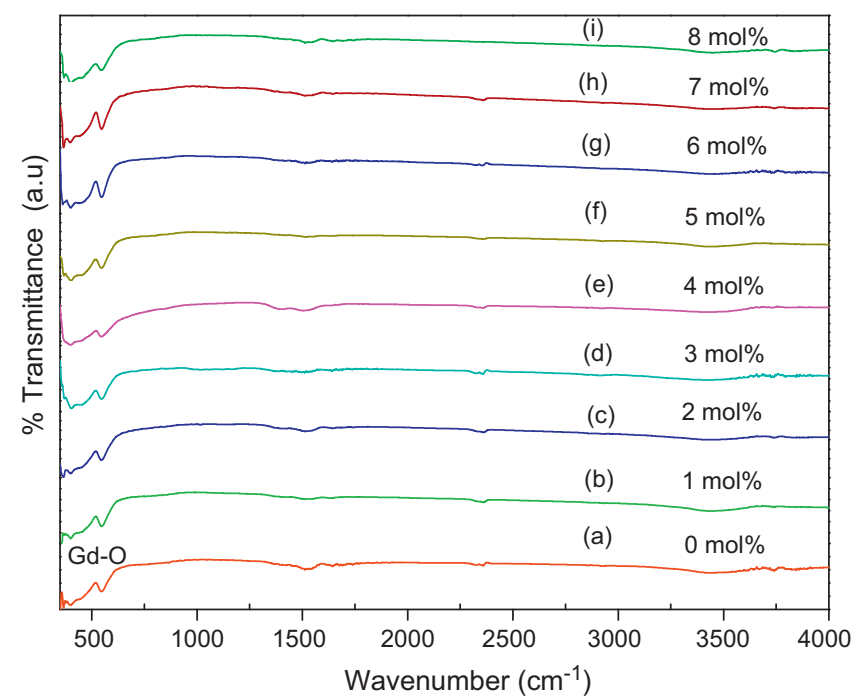

Fig. 5. FT-IR spectra of $\mathrm{Gd}_{2} \mathrm{O}_{3}: \mathrm{Eu}^{3+}: \mathrm{Li}^{+}(0-8 \mathrm{~mol} \%)$ phosphors calcined at $800{ }^{\circ} \mathrm{C}(3 \mathrm{~h})$.

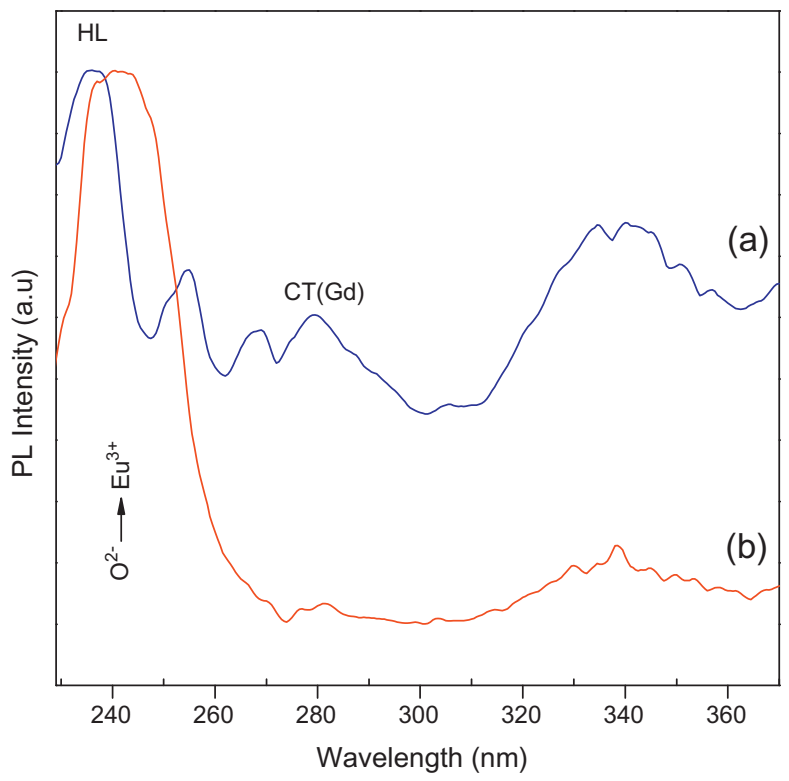

Fig. 6. Excitation spectra of (a) $\mathrm{Gd}_{2} \mathrm{O}_{3}: \mathrm{Eu}^{3+}$ and (b) $\mathrm{Gd}_{2} \mathrm{O}_{3}: \mathrm{Eu}^{3+}: \mathrm{Li}^{+}(6 \mathrm{~mol} \%)$. from $\mathrm{O}^{2-} 2 \mathrm{p}$ state to $\mathrm{Eu}^{3+} 4 \mathrm{f}$ state [18]. The peak near $240 \mathrm{~nm}$ originates from the excitation of $\mathrm{Gd}_{2} \mathrm{O}_{3}$ host lattice (HL). The HL and CT peak of the doped samples were improved distinctly in comparison with that of un-doped sample. It is noticeable that CT peak was almost unchanged in $\mathrm{Li}^{+}$-doped samples. Lopez et al. [22] reported that the oxygen vacancy might act as a sensitizer for the energy transfer to the rare-earth ions owing to the strong mixing of CT states. Hence the second aspect can be ascribed to the creation of oxygen vacancies due to $\mathrm{Gd}^{3+}$ sites occupied by smaller $\mathrm{Li}^{+}$ions, resulting in the improvement of luminescent intensity.

It is observed that the host lattice peak in $\mathrm{Li}^{+}$co-doped $\mathrm{Gd}_{2} \mathrm{O}_{3}: \mathrm{Eu}^{3+}$ is shifted $(\sim 10 \mathrm{~nm})$ towards higher wavelength side when compared to un-doped $\mathrm{Li}^{+}$. In emission spectrum $\left(\lambda_{\text {exi }}=254 \mathrm{~nm}\right)$ (Fig. 7), the strongest peak situated at $612 \mathrm{~nm}$ is assigned to the ${ }^{5} \mathrm{D}_{0} \rightarrow{ }^{7} \mathrm{~F}_{2}$ transition of $\mathrm{Eu}^{3+}$ ions, and the peak around $588 \mathrm{~nm}$ is related to ${ }^{5} \mathrm{D}_{0} \rightarrow{ }^{7} \mathrm{~F}_{1}$ transition. The peaks from ${ }^{5} \mathrm{D}_{1} \rightarrow{ }^{7} \mathrm{~F}_{J}(J=1,2)$ transitions were also detected in the range of $525-570 \mathrm{~nm}$. It is obvious that the PL intensity of $\mathrm{Gd}_{2} \mathrm{O}_{3}: \mathrm{Eu}^{3+}$ nanophosphor can be enhanced drastically by co-doping with $\mathrm{Li}^{+}$ ions. Comparing with the un-doped samples, the PL intensities are improved 4 times for $\mathrm{Li}^{+}$co-doped $\mathrm{Gd}_{2} \mathrm{O}_{3}: \mathrm{Eu}^{3+}$ nanophosphors. The influence of the $\mathrm{Li}^{+}$ions on the luminescent performance may be attributed to several aspects. Firstly and the most obvious one is the flux effect of the $\mathrm{Li}^{+}$. It gives a better crystallization and larger grain size, resulting in higher oscillating strengths for the optical transitions [23], and also reducing the luminescence quenching due to the surface states [13], thus bringing on the increase of the luminescent intensity. In addition, $\mathrm{Li}^{+}$ions promote the structured transforma-

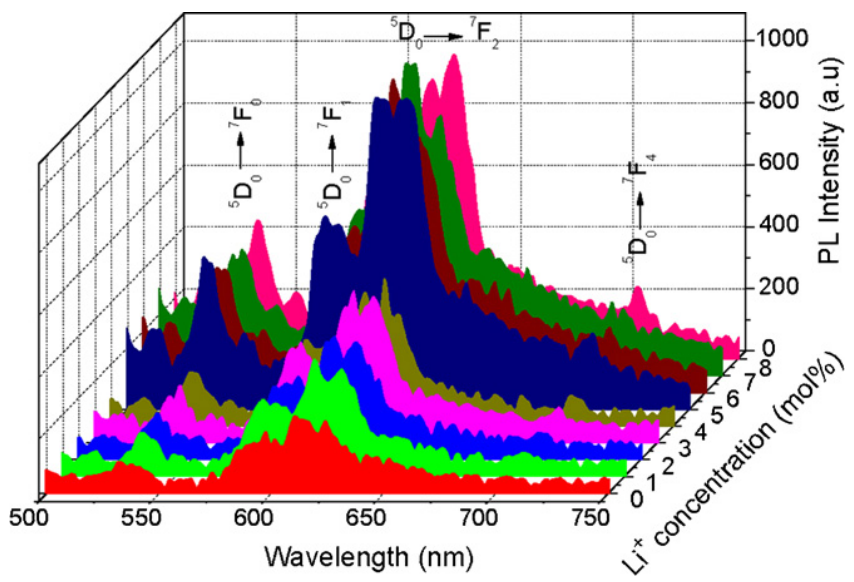

Fig. 7. PL emission spectra of $\mathrm{Gd}_{2} \mathrm{O}_{3}: \mathrm{Eu}^{3+}: \mathrm{Li}^{+}(0-8 \mathrm{~mol} \%)$ nanophosphors calcined at $800^{\circ} \mathrm{C}$ for $3 \mathrm{~h}$. 


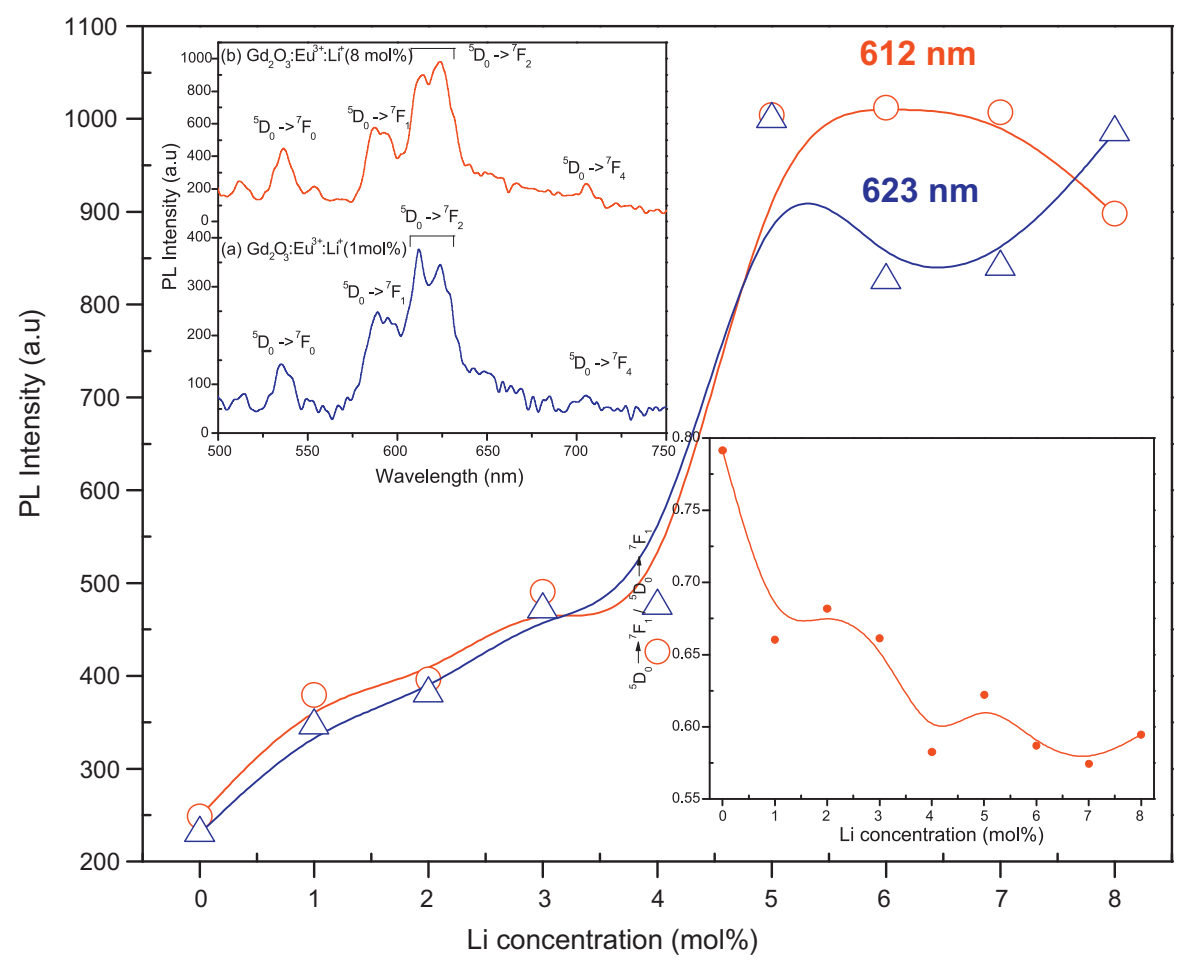

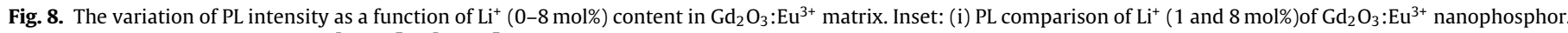
(ii) The variation of $612 / 623$ peaks $\left({ }^{5} \mathrm{D}_{0} \rightarrow{ }^{7} \mathrm{~F}_{1} /{ }^{5} \mathrm{D}_{0} \rightarrow{ }^{7} \mathrm{~F}_{2}\right)$ as a function of $\mathrm{Li}^{+}$concentrations.

tion from monoclinic to cubic $\mathrm{Gd}_{2} \mathrm{O}_{3}: \mathrm{Eu}^{3+}$. This structural change is favorable for luminescence. The effective ionic radius of $\mathrm{Li}^{+}(0.76 \AA)$ ion is smaller than that of $\mathrm{Gd}^{3+}$ ion $(0.94 \AA)$ and therefore the $\mathrm{Li}^{+}$ ions are suitable for occupation of the $\mathrm{Gd}^{3+}$ sites, which will give rise to a number of oxygen vacancies for the charge neutrality.

When the concentration of $\mathrm{Li}^{+}$ion is below $4 \mathrm{~mol} \%$, substituting $\mathrm{Gd}^{3+}$ ions with $\mathrm{Li}^{+}$ions can induced oxygen vacancy due to charge compensation, so the substitutional site $\mathrm{Li}^{+}$ions and oxygen vacancies around $\mathrm{Eu}^{3+}$ ions can cause the crystal field distortion. However, for higher concentration of $\mathrm{Li}^{+}$the substitutional site and the interstitial site $\mathrm{Li}^{+}$ions co-exist in the host. These interstitial $\mathrm{Li}^{+}$ions would induce the $\mathrm{Gd}^{3+}$ vacancies so there are four different types of defects around the $\mathrm{Eu}^{3+}$ ions, which cause much severe crystal field distortion. When the content of $\mathrm{Li}^{+}$is above $4 \mathrm{~mol} \%$, the increase of emission peaks that stark levels have been split, which proves that with the appearance of interstitial $\mathrm{Li}^{+}$the crystal field symmetry around $\mathrm{Eu}^{3+}$ have been seriously broken.

Fig. 8 shows the PL intensity of the ${ }^{5} \mathrm{D}_{0} \rightarrow{ }^{7} \mathrm{~F}_{1}(612 \mathrm{~nm})$ and ${ }^{5} \mathrm{D}_{0} \rightarrow{ }^{7} \mathrm{~F}_{2}(623 \mathrm{~nm})$ transition of the $\mathrm{Gd}_{2} \mathrm{O}_{3}: \mathrm{Eu}^{3+}(4 \mathrm{~mol} \%)$ nanophosphor as a function of $\mathrm{Li}^{+}(0-8 \mathrm{~mol} \%)$ doping concentration. It can be seen that the intensities of the ${ }^{5} \mathrm{D}_{0} \rightarrow{ }^{7} \mathrm{~F}_{2}$ transitions are always higher than that of the ${ }^{5} \mathrm{D}_{0} \rightarrow{ }^{7} \mathrm{~F}_{1}$ transitions irrespective of the $\mathrm{Li}^{+}$concentration. The emission intensity resulting from the ${ }^{5} \mathrm{D}_{0} \rightarrow{ }^{7} \mathrm{~F}_{1}$ and ${ }^{5} \mathrm{D}_{0} \rightarrow{ }^{7} \mathrm{~F}_{2}$ transitions are prominently enhanced after substitution of ( $4 \mathrm{~mol} \%) \mathrm{Eu}^{3+}$ by $\mathrm{Li}^{+}$and the emission intensity further increases with the $\mathrm{Li}^{+}$concentration obtaining its maximum at $6 \mathrm{~mol} \% \mathrm{Li}^{+}$, then slightly decrease. This phenomenon is probably due to the fact that low fraction of $\mathrm{Li}^{+}$substitution in the lattice induce the fast energy transfer from the host to the $\mathrm{Eu}^{3+}$ ions and a decrease in interstitial oxygen, and hence conducting an increase in the hole concentration leading to a decrease in competitive absorption and as a result to a higher quantum yield [24]. On the other hand the doping of $\mathrm{Li}^{+}$might also give rise to the formation of defective structure. Once $\mathrm{Li}^{+}$attains a certain concentration ( 5,6 and $7 \mathrm{~mol} \%$ ), the defects in the host lattice greatly increase, which would unavoidably reduce the crystallinity and increase the unactive center concentration, thus leads to the luminescence quenching [25].

Therefore, the PL intensity has great dependence on co-activator concentration. The brightness increases with co-activator concentration to certain extent, if above this point, the luminescence begins to decrease, due to parity or aggregation of co-activator atoms at high concentration which leads to efficient resonant energy transfer between $\mathrm{Eu}^{3+} / \mathrm{Li}^{+}$ions and a fraction of energy migration to distant killer or quenchers, then quenching behavior appears as a result.

The PL intensity ratios of the ${ }^{5} \mathrm{D}_{0} \rightarrow{ }^{7} \mathrm{~F}_{1}$ transition to the ${ }^{5} \mathrm{D}_{0} \rightarrow{ }^{7} \mathrm{~F}_{2}$ transitions at various $\mathrm{Li}^{+}$concentrations are shown in inset of Fig. 8. It is well known that the ${ }^{5} \mathrm{D}_{0} \rightarrow{ }^{7} \mathrm{~F}_{2}$ transition is allowed when $\mathrm{Eu}^{3+}$ embedded at a site of non-inversion symmetry while ${ }^{5} \mathrm{D}_{0} \rightarrow{ }^{7} \mathrm{~F}_{1}$ transition is allowed at a site with inversion symmetry. Hence, the PL intensity ratio ${ }^{5} \mathrm{D}_{0} \rightarrow{ }^{7} \mathrm{~F}_{1} /{ }^{5} \mathrm{D}_{0} \rightarrow{ }^{7} \mathrm{~F}_{2}$ called as symmetric ratio, gives a measure of the degree of distortion from inversion symmetry of the local environment surrounding the $\mathrm{Eu}^{3+}$ ions in the host matrix [26]. However, it is reasonable to believe that the doping of $\mathrm{Li}^{+}$will introduce lattice defects, which will undoubtedly reduce the symmetry strength of the local environment of $\mathrm{Eu}^{3+}$. Consequently, the symmetry ratio of $\mathrm{Gd}_{2} \mathrm{O}_{3}: \mathrm{Eu}^{3+}: \mathrm{Li}^{+}$ decreases with the increase of doped $\mathrm{Li}^{+}$concentration (inset Fig. 8).

Fig. 9(a-e) shows the $\mathrm{Gd}_{2} \mathrm{O}_{3}: \mathrm{Eu}^{3+}: \mathrm{Li}^{+}(4 \mathrm{~mol} \%)$ nanophosphor heat treated at different temperatures from $500-900^{\circ} \mathrm{C}$. The PL intensity of ${ }^{5} \mathrm{D}_{0} \rightarrow{ }^{7} \mathrm{~F}_{1}$ and ${ }^{5} \mathrm{D}_{0} \rightarrow{ }^{7} \mathrm{~F}_{2}$ transition plotted as a function of calcinations temperature is shown in Fig. 10. It is observed that, PL intensity increases with increase of calcinations temperature. The crystal structure of the sample observed at low-temperature is faintly disorder and quenching centers, resulting in better emission. However, when temperature is raised over the certain point, this effect becomes less prominent and as a result the emission intensity reaches its saturations. For the enhanced PL intensity, it can be suggested that the incorporation of $\mathrm{Li}^{+}$ions creates the oxygen vacancies, which might act as a sensitizer for the effective energy transfer due to the strong mixture of charge transfer states [18]. 


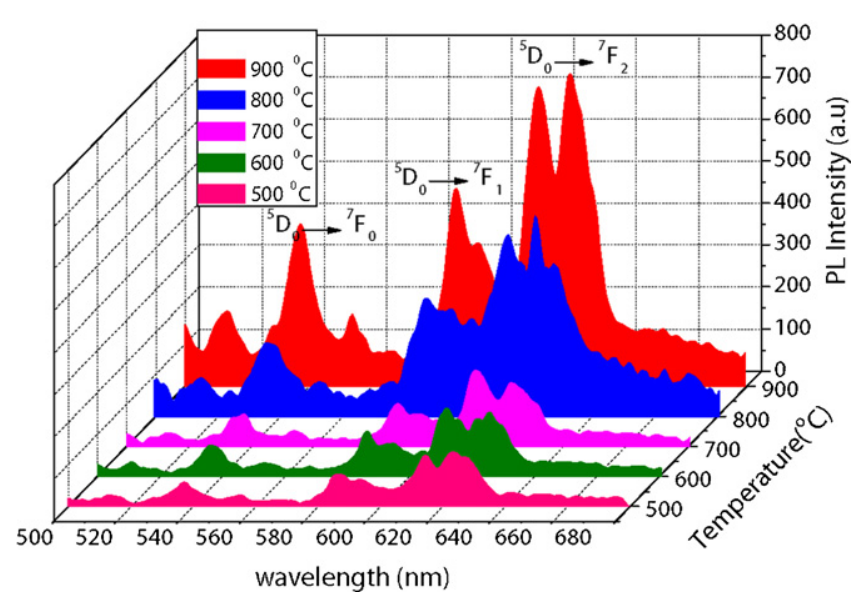

Fig. 9. PL emission spectra of $\mathrm{Gd}_{2} \mathrm{O}_{3}: \mathrm{Eu}^{3+}: \mathrm{Li}^{+}(4 \mathrm{~mol} \%)$ nanophosphors calcined at different temperature for $3 \mathrm{~h}$.

The UV-VIS absorption spectra of $\mathrm{Li}^{+}(0-8 \mathrm{~mol} \%) \mathrm{Gd}_{2} \mathrm{O}_{3}: \mathrm{Eu}^{3+}$ are shown in Fig. 11. Both of the spectra have strong absorption in the UV spectral region and some were peaks of intra- $4 \mathrm{f}$ transitions of $\mathrm{Eu}^{3+}$ at lower wavelength. The $\mathrm{Li}^{+}$-doped sample exhibits a visible increase of absorbance and an obvious red-shift of the absorption edge compared with the one without $\mathrm{Li}^{+}$doping. It has been known that the position of the absorption edge is determined by the width of forbidden band with $\mathrm{O} 2 \mathrm{p}$ orbits as the valence band in multi component oxides. Occupation of $\mathrm{Gd}^{3+}$ sites by $\mathrm{Li}^{+}$ions would naturally give rise to a substantial number of oxygen vacancies, which may change the energy band structure and enhance the deformation degree of 02 p orbits and the superposition of the electronic wave functions, and then result in narrowing the forbidden band and shifting the absorption edge to the red.

The optical band gap energy $\left(E_{g}\right)$ (Fig. 12 ) was estimated by the method proposed by Tauc [27]. According to these authors, the optical band gap is estimated with absorption co-efficient and photon energy by the following equation

$h v \alpha \propto\left(h v-E_{\mathrm{g}}\right)^{k}$

where $\alpha$ is the absorption co-efficient, $h$ is the Planks constant, $v$ is the frequency, $E_{\mathrm{g}}$ is the optical band gap and $k$ is the constant associated to the different types of electronic transitions $k=1 / 2$,

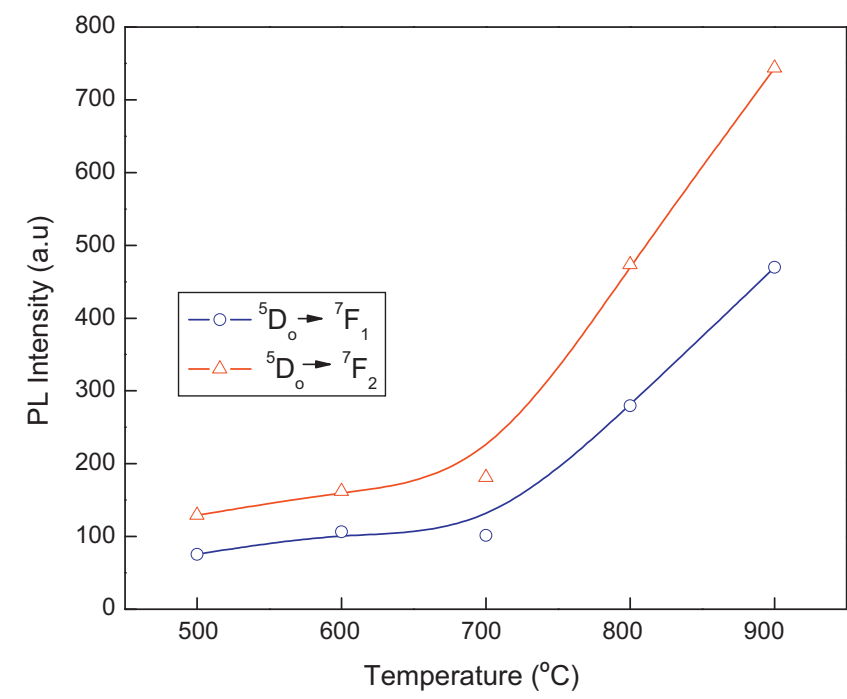

Fig. 10. The variation of PL intensity of ${ }^{5} \mathrm{D}_{0} \rightarrow{ }^{7} \mathrm{~F}_{1}$ and ${ }^{5} \mathrm{D}_{0} \rightarrow{ }^{7} \mathrm{~F}_{2}$ transition as a function of calcination temperature $(3 \mathrm{~h})$.

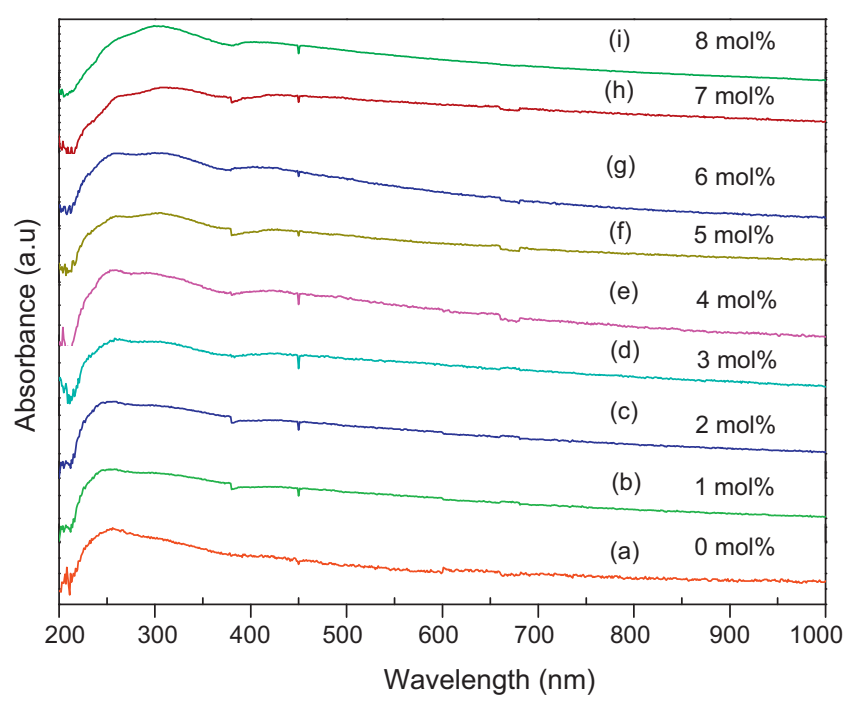

Fig. 11. UV-VIS spectra of $\mathrm{Gd}_{2} \mathrm{O}_{3}: \mathrm{Eu}^{3+}: \mathrm{Li}^{+}(0-8 \mathrm{~mol} \%)$ phosphors calcined at $800{ }^{\circ} \mathrm{C}$ (3h).

2, 3/2, 3 for direct allowed, indirect allowed, direct forbidden and indirect forbidden transitions respectively. According to literature [28] the oxides are characterized by an indirect allowed electronic transition and hence, the $k=2$ value was adopted as standard in Eq. (3). Thus the $E_{\mathrm{g}}$ values was evaluated extrapolating the linear portion of the curve or tail [ $\left.(h v \alpha)^{1 / k}=0\right]$ in the UV-VIS absorbance spectra. A plausible explanation for the variations observed in the $E_{\mathrm{g}}$ values can be related to the degree of structural order-disorder in to the lattice, which is able to change the intermediary energy level distribution within the band gap. The variations in the band gap values might also be due to higher degree of structural defects, while the phosphors heat treated from 500 to $900^{\circ} \mathrm{C}$, the absorption spectra shows more ordered/crystalline materials (inset Fig. 13). On the basis of these information, if the structure becomes more ordered with the heat treated temperature i.e. when the concentration of structural defects (oxygen vacancies, distortions and/or strains in the lattice) is reduced. The presence of intermediary energy levels (deep and shallow holes) is minimized within the optical band gap and consequently, the $E_{\mathrm{g}}$ values increase. As it can be seen, the energy gap values (Table 1 ) are mainly depends on the

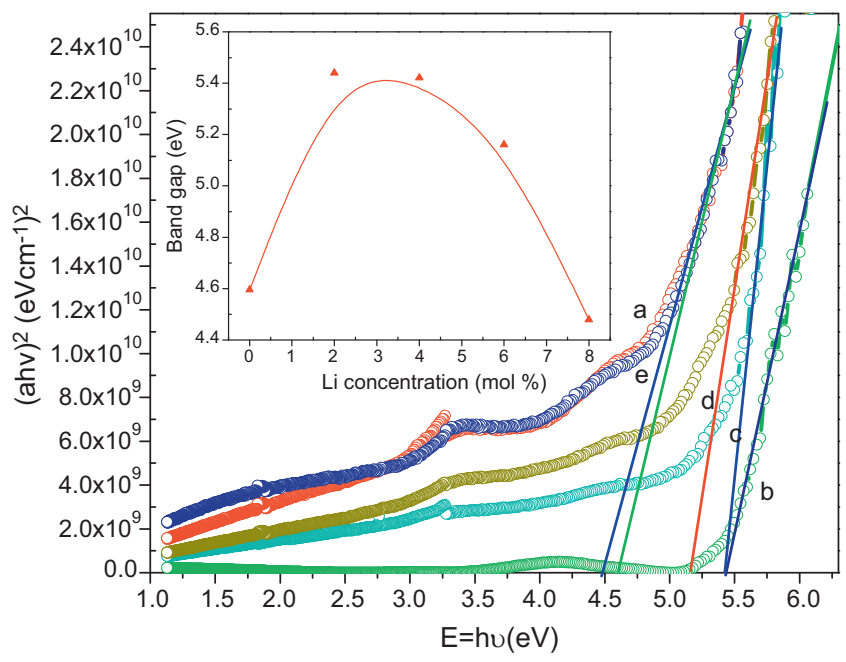

Fig. 12. Energy gap of $\mathrm{Gd}_{2} \mathrm{O}_{3}: \mathrm{Eu}^{3+}: \mathrm{Li}^{+}$phosphors calcined at $800{ }^{\circ} \mathrm{C}(3 \mathrm{~h})$ (a) without $\mathrm{Li}^{+}$, (b) $2 \mathrm{~mol} \%$, (c) $4 \mathrm{~mol} \%$, (d) $6 \mathrm{~mol} \%$ and (e) $8 \mathrm{~mol} \%$ respectively (inset: band gap vs. $\mathrm{Li}^{+}$concentration). 


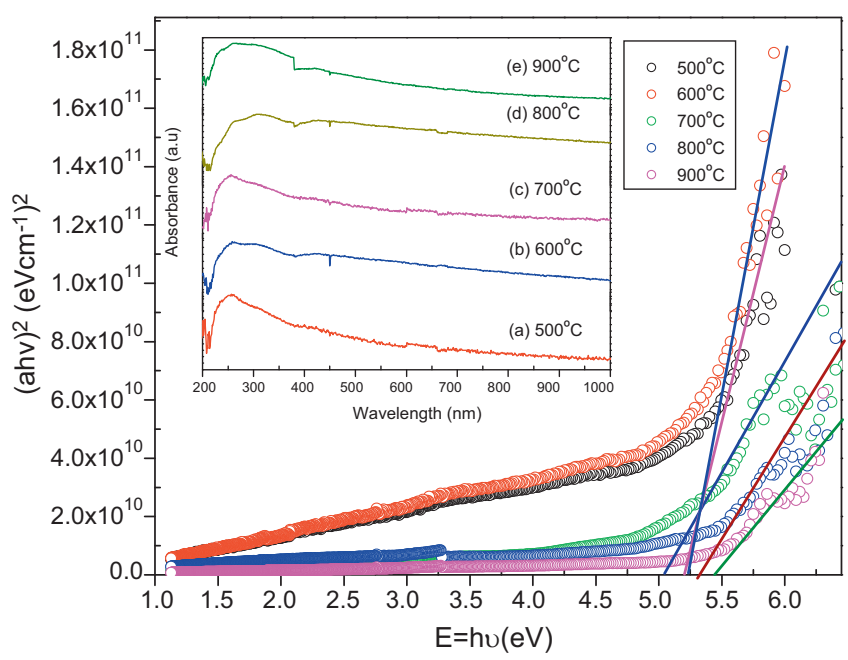

Fig. 13. Energy gap of $\mathrm{Gd}_{2} \mathrm{O}_{3}: \mathrm{Eu}^{3+}: \mathrm{Li}^{+}$phosphors calcined at different temperature (a) $500^{\circ} \mathrm{C}$, (b) $600^{\circ} \mathrm{C}$, (c) $700^{\circ} \mathrm{C}$, (d) $800^{\circ} \mathrm{C}$ and (e) $900^{\circ} \mathrm{C}$ (inset: UV-VIS absorption spectra).

preparation methods and experimental conditions (heat-treated and processing time). In particular, these key factors can favor or inhibit the formation of structural defects, which are able to control the degree of structural order-disorder in the material and consequently, the number of intermediary energy levels within the band gap.

\section{Conclusions}

$\mathrm{Li}^{+}$co-doped (0-8 mol\%) $\mathrm{Gd}_{2} \mathrm{O}_{3}: \mathrm{Eu}^{3+}$ red phosphors have been prepared through solution combustion synthesis. The improvement of the crystallinity and decrease of particle size induced by the addition of $\mathrm{Li}^{+}$ions has been observed. When $\mathrm{Li}^{+}$was codoped, the PL intensity of $\mathrm{Gd}_{2} \mathrm{O}_{3}$ : $\mathrm{Eu}^{3+}$ phosphor is enhanced. This is due to charge compensation resulting from the substitution effect of $\mathrm{Li}^{+}$ions to $\mathrm{Gd}^{3+}$ and also due to lowering of local symmetry that was induced by the $\mathrm{Li}^{+}$ions. The luminescence spectra consists of a dominant red emission peak at $612 \mathrm{~nm}$, which corresponds to the transition of ${ }^{5} \mathrm{D}_{0} \rightarrow{ }^{7} \mathrm{~F}_{2}$ of $\mathrm{Eu}^{3+}$ ions. The higher PL emission intensity was observed in $6 \mathrm{~mol} \% \mathrm{Li}^{+}$whose brightness was increased by 4 times when compared to that of $\mathrm{Gd}_{2} \mathrm{O}_{3}: \mathrm{Eu}^{3+}$. The improvement in the PL efficiency with the $\mathrm{Li}^{+}$doping may result from improved crystallinity leading to higher oscillating strengths for the optical transitions. Further, it can also be suggested that the incorporation of $\mathrm{Li}^{+}$creates the oxygen vacancies, which might act as a sensitizer for the effective energy transfer due to strong charge transfer states. Thus the red emitting $\mathrm{Li}^{+}-$ doped $\mathrm{Gd}_{2} \mathrm{O}_{3}$ : $\mathrm{Eu}^{3+}$ phosphors are promising for possible display applications.

\section{Acknowledgments}

The authors are grateful to TEQIP Lab of M.S. Ramaiah Institute of Technology, Bangalore for providing facilities for preparation of materials. One of the authors N.D. acknowledges Management, Principal and HOD, B.M.S. Institute of Technology, Bangalore for the support and encouragement. The author H.N. thanks to Dr. S.C. Sharma, Vice-chancellor, Tumkur University, Tumkur, for constant encouragement and support.

\section{References}

[1] J.H. Jeong, H. Koung Yang, B.K. Moon, J. Seong Bae, S.S. Yi, H.C.J. Hwan Kim, S.T Chung, Opt. Mater. 28 (2006) 693.

[2] J.S. Bae, S.B. Kim, J.H. Jeong, J.C. Park, D.K. Kim, S.H. Byeon, S.S. Yi, Thin Solid Films 471 (2005) 224.

[3] T. Takeda, D. Koshiba, S. Kikkawa, J. Alloys Compd. 408 (2006) 879.

[4] D. Paul Joseph, P. Renugambal, M. Saravanan, S. Philip Raja, C. Venkateswaran, Thin Solid Films 517 (2009) 6129.

[5] S.H. Shin, J.H. Kang, D.Y. Jeon, D.S. Zang, J. Lumin. 114 (2005) 275.

[6] T. Dhannia, S.J Ayalekshmi, M.C. Santhosh Kumar, T Prasada Rao, A. Chandra Bose, J. Phys. Chem. Solids 71 (2010) 1020.

[7] L.D. Sun, C.S. Liao, C.H. Yan, J. Solid State Chem. 117 (2003) 304

[8] R.P. Rao, Solid State Commun. 99 (1996) 439.

[9] R.P.S. Chakradhar, B.M. Nagabhushana, G.T. Chandrappa, J.L. Rao, J. Chem. Phys. 121 (2004) 10250.

[10] B. Umesh, B. Eraiah, B.M. Nagabhushana, H. Nagabhushana, H.B. Premkumar, C. Shivakumara, Chikkahanumantharayappa, R.P.S. Chakradhar, Phil. Mag. Lett. 89 (2009) 589.

[11] H. Nagabhushana, B.M. Nagabhushana, M. Kumar, H.B. Premkumar, C. Shivakumara, R.P.S. Chakradhar, Phil. Mag. 90 (2010) 3567.

[12] N. Dhananjaya, H. Nagabhushana, B.M. Nagabhushana, R.P.S. Chakradhar, C. Shivakumara, B. Rudraswamy, Physica B 405 (2010) 3795.

[13] H.S. Peng, H.W. Song, B.J. Chen, J.W. Wang, S.Z. Lu, X.G. Kong, J.H. Zhang, J. Chem Phys. 118 (2003) 3277

[14] X.D. Sun, X.D. Xiang, Appl. Phys. Lett. 72 (1998) 525.

[15] B.M. Nagabhushana, Combustion synthesis, characterization and study of magnetic properties of alkaline earth substituted lanthanum manganits, Ph.D. Thesis, Bangalore University, 2008

[16] P. Klug, L.E Alexander, X-ray Diffraction Procedure, Wiley, New York, 1954.

[17] G.K. William, W.H. Hall, Acta Metall. 1 (1953) 22

[18] B. Liu, M. Gu, X. Liu, C. Ni, D. Wang, L. Xiao, R. Zhang, J. Alloys Compds. 440 (2007) 341.

[19] Hongwu Zhang, Xiaoyan Fu, Shuyun Niu, Gongquan Sun, Qin Xin, J. Lumin. 115 (2005) 7.

[20] H.K. Yang, H. Choi, B.K. Moon, B.C. Choi, J.H. Jeong, J.H. Kim, K.H. Kim, Solid State Sci. 12 (2010) 1445

[21] S.H. Shin, J.H. Kang, D.Y. Jeon, S.H. Choi, S.H. Lee, Y.C. You, D.S. Zang, Solid State Commun. 135 (2005) 30

[22] O.A. Lopez, J. McKittrick, L.E. Shea, J. Lumin. 71 (1997) 1.

[23] K.C. Misbra, J.K. Berkowitz, K.H. Johnson, P.C. Schmidt, Phys. Rev. B 45 (1992) 10902.

[24] S.S. Yi, J.S. Bae, K.S. Shim, J.H. Jeong, J.C. Park, P.H. Holloway, Appl. Phys. Lett. 84 (2004) 353.

[25] X.L. Liu, X. Xui, M. Gu, L.H. Xiao, K. Han, R. Zhang, Appl. Surf. Sci. 253 (2007) 4344.

[26] G. Hebbink, J. Stouwdam, D. Reinhoudt, E. Beggel, Adv. Mater. 14 (2002) 1147.

[27] J. Tauc, in: F. Abeles (Ed.), Optical Properties of Solids, North-Holland, Amsterdam, 1970.

[28] X. Liu, F. Zhou, M. Gu, S. Huang, B. Liu, C. Ni, Opt. Mater. 31 (2008) 126. 